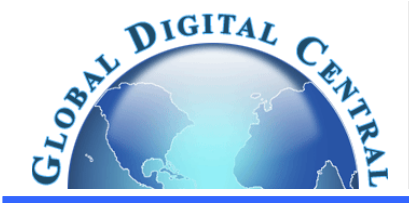

Frontiers in Heat and Mass Transfer

Available at www.ThermalFluidsCentral.org

\title{
MHD FLOW AND HEAT TRANSFER IN A WILLIAMSON FLUID FROM A VERTICAL PERMEABLE CONE WITH THERMAL AND MOMENTUM SLIP EFFECTS: A MATHEMATICAL STUDY
}

\author{
CH. Amanulla ${ }^{a, b^{*}}$, N. Nagendra ${ }^{a}$, M. Suryanarayana Reddy ${ }^{b}$ \\ ${ }^{a}$ Department of Mathematics, Madanapalle Institute of Technology and Science, Madanapalle-517325, India. \\ ${ }^{b}$ Department of Mathematics, JNTUA College of Engineering, Pulivendula-516390, Andhra Pradesh, India.
}

\begin{abstract}
A theoretical and computational study of the magneto hydrodynamic flow and free convection heat transfer in an electro-conductive polymer on the external surface of a vertical permeable cone under radial magnetic field is presented. Thermal and velocity (hydrodynamic) slip are considered at the vertical permeable cone surface via modified boundary conditions. The Williamson viscoelastic model is employed which is representative of certain industrial polymers. The non-dimensional, transformed boundary layer equations for momentum and energy are solved with the second order accurate implicit Keller box finite difference method under appropriate boundary conditions. Validation of the numerical solutions is achieved via benchmarking with earlier published results. The influence of Weissenberg number (ratio of the relaxation time of the fluid and time scale of the flow), magnetic body force parameter, stream wise variable and Prandtl number on thermo-fluid characteristics are studied graphically and via tables. A weak elevation in temperature accompanies increasing Weissenberg number whereas a significant acceleration in the flow is computed near the cone surface with increasing Weissenberg number. Nusselt number is reduced with increasing Weissenberg number. Skin friction is increased whereas Nusselt number is reduced with greater stream wise coordinate. The study is relevant to smart coating transport phen omena.
\end{abstract}

Keywords: Magneto-hydrodynamics; Thermal convection; Weissenberg number; Vertical Permeable Cone; thermal and momentum slip.

\section{INTRODUCTION}

Magneto-hydrodynamics has found ever-increasing applications in modern smart technologies. The application of magnetic fields (static or alternating) has been shown to manipulate successfully the material characteristics of electro-conductive polymers which are finding new applications in aerospace, offshore and naval industries. Interesting studies in this regard addressing various systems employing magnetic polymers include environmental engineering (2011), thin film fabrication processes (2014) and design of shock dissipation systems with magnetic elastomers (2007). Coating applications and energy systems enhancement with smart magnetic polymers have also grown substantially in recent years. Relevant technologies in this regard are nuclear engineering (1998), medical engineering exploiting stimulibased polymers (2010) and hydromagnetic energy generation (2008). In the context of coating applications, it is critical to regulate heat transfer conditions which lead to improved bonding and homogeneity in engineered polymeric surfaces. Many studies have therefore examined the transport phenomena (i.e. coupled heat and momentum transfer) from different geometrical shapes including cones, pipes, disks and truncated bodies and spheres. The spherical geometry is particularly relevant to chemical engineering processes. Investigators have applied a variety of different material models for the coatings and also numerical methods to solve the associated boundary value problems. Bég et al. (2012) used the homotopy analysis method (HAM) to analyze flow from a sphere in a porous medium. Na and Chiou (1979) used a Quasilinearization method to simulate the laminar natural convection over frustum convection about a truncated cone. Noghrehabadi et al. (2013) studied the natural convection flow of nanofluids over a vertical cone embedded in non-Darcy porous media.
The above studies were confined to Newtonian fluids. However, generally polymers are known to exhibit non-Newtonian characteristics. Engineers have therefore developed a variety of constitutive models to analyse the shear stress-strain characteristics of these fluids, including viscoplastic, viscoelastic, micro-structural and power-law models. Both purely fluid flow and heat transfer from a sphere to non-Newtonian fluids have been reported in a number of theoretical investigations. Radiation effect on natural convection about a truncated cone were examined by Yih (1999). Harish Babu and Satya Narayana (2016) examined the radiative flow of Jeffery fluid in a stretching porous sheet with power law heat flux and heat source. Satya Narayana and Venkateswarlu (2016) have studied heat and mass transfer on MHD nanofluid flow past a vertical porous plate in a rotating system. Fluid flow and radiative nonlinear heat transfer over a stretching sheet has been investigated by Satya Narayana and Harish Babu (2016). Venkateswarlu and Satya Narayana (2016) have analysed the chemical reaction, Soret and Dufour effects on the flow and heat transfer of a Casson fluid in a stretching surface. Hossain and Paul (2001) reported the free convection past a vertical permeable circular cone with nonuniform surface temperature. Amanulla et al. (2017) investigated slip effects on non-Newtonian Nanofluid flow from an Isothermal sphere. They analyzed the behavior of fluid on velocity and temperature distributions when thermal and velocity slips are considered. Pop and $\mathrm{Na}$ (1999) presented the heat and mass transfer by natural convection about a truncated cone in the presence of magnetic field and radiation effects. Cheng (2011) studied the natural convection boundary layer flow of a micropolar fluid over a vertical permeable cone with variable temperature. Nadeem and Saleem (2015) presented analytical solutions of third grade fluid over a rotating vertical cone in the presence of nanop articles.

\footnotetext{
* Corresponding author. Email: amanu.sh@yahoo.com
} 
These studies however did not consider the Williamson model. This is a shear-thinning non-Newtonian model which quite accurately simulates polymer viscoelastic flows over a wide spectrum of shear rates. In Williamson fluids the viscosity is reduced with rising shear stress rates. This model has found some popularity in engineering simulations. Prasannakumara et al. (2016) used the Runge-Kutta-Fehlberg shooting algorithm to analyse reactive-radiative flow of Williamson viscoelastic nanofluid from a stretching sheet in a permeable material. Khan and Khan (2014) investigated Blasius, Sakiadis, stretching and stagnation point flows of Williamson fluid using the homotopy analysis method, over a range of Weissenberg numbers. Bég et al. (2013) presented extensive numerical solutions for hydromagnetic pumping of a Williamson fluid using a modified differential transform method, observing that a change in Weissenberg number strongly modifies the pressure difference and axial velocity. Further studies of transport phenomena in Williamson fluids include Rao and Rao (2014), Rao et al. (2017) and Dapra and Scarpi (2007).

In the present investigation, we consider the magnetohydrodynamic convection boundary layer flow of a Williamson polymeric fluid external to a vertical permeable cone with multiple slip effects. Magnetic fields have been found to profoundly influence heat transfer and velocity characteristics in curved body flows. Relevant examples include Bég et al. (2014) (for cylindrical geometries), Alkasasbeh et al. (2014) who addressed radiative effects also, Rao et al. (2017) who considered Partial Slip effects and Kasim et al. (2013) who used a viscoelastic model. Slip effects have been shown to be prominent in certain polymeric flow processes. Momentum (hydrodynamic) slip relates to the non-adherence of the polymer to a solid boundary and arises in polymer melts, emulsions, petro-chemical suspensions and also foams (1998, 1994, 1995, 1989, 1993, 1992, 2000, 1991, 1992). The presence of momentum slip invalidates the classical "no-slip" boundary condition. Thermal slip may also arise in heat transfer problems and can also significantly modify both velocity and temperature characteristics both at the solid surface and deeper into the boundary layer. Several researchers have examined multi-physical flows with velocity and/or thermal slip effects including Jamil and Khan (2001), Tripathi et al. (2014) (for viscoelastic fluids), Bég et al. (2014) for magnetohydrodynamic heat and mass transfer and Devi and Devi (2011) for swirling disk hy dromagnetic flows with cross diffusion. Sreenadha et al. (2014) have studied analytically the wall slip effects in peristaltic propulsion and heat transfer of Williamson fluids in inclined conduits. The present study employs a finite difference numerical method due to Keller for solving the two-dimensional steady slip flow and heat transfer in a Williamson polymeric liquid boundary layer from a vertical permeable cone. Verification of the computations is conducted for the special case of non-magnetic, Newtonian flow in the absence of slip with earlier published literature. The study finds applications in electro-conductive thermal polymer processing systems.

\section{MAGNETOHYDRODYNAMIC VISCOELASTIC SLIP THERMOFLUID MODEL}

The regime under investigation is illustrated in Fig. 1. Steady, incompressible hydromagnetic Williamson non-Newtonian boundary layer flow and heat transfer from vertical cone body under radial magnetic field is considered. For an incompressible Williamson fluid, the continuity (mass conservation) and momentum equations are given as:

$\operatorname{div} \mathrm{V}=0$,

$\rho \frac{\mathrm{dV}}{\mathrm{dt}}=\operatorname{divS}+\rho b$

Where $\rho$ is the density of the fluid, $\mathrm{V}$ is the velocity vector, $\mathrm{S}$ is the Cauchy stress tensor, $b$ represents the specific body force vector, and $\mathrm{d} / \mathrm{dt}$ represents the material time derivate. The constitutive equations of the Williamson fluid model (2016, 2014, 2013, 2007) are given as:

$\mathrm{S}=-\mathrm{pI}+\tau$

$\tau=\left[\mu_{\infty}+\frac{\left(\mu_{0}-\mu_{\infty}\right)}{1-\Gamma \dot{\gamma}}\right] A_{1}$,

Here $\mathrm{P}$ is the pressure, $\mathrm{I}$ is the identity vector, $\tau$ is the extra stress tensor, $\mu_{0}$ are the limiting viscosities at zero and at infinite shear rate, $\Gamma$ is the time constant $(>0), \mathrm{A}_{1}$ is the first Rivlin-Erickson tensor and $\dot{\gamma}$ is defined as follows:

$\begin{aligned} \dot{\gamma} & =\sqrt{\frac{1}{2} \pi} \\ \pi & =\operatorname{trace}\left(A_{1}^{2}\right)\end{aligned}$

Here we considered the case for which $\mu_{\infty}=0$ and $\Gamma \dot{\gamma}<1$. Thus eq.

(4) can be written as:

$\tau=\left[\frac{\left(\mu_{0}-\mu_{\infty}\right)}{1-\Gamma \dot{\gamma}}\right] A_{1}$

Or by using binomial expansion we get:

$\tau=\mu_{0}[1+\Gamma \dot{\gamma}] A_{1}$

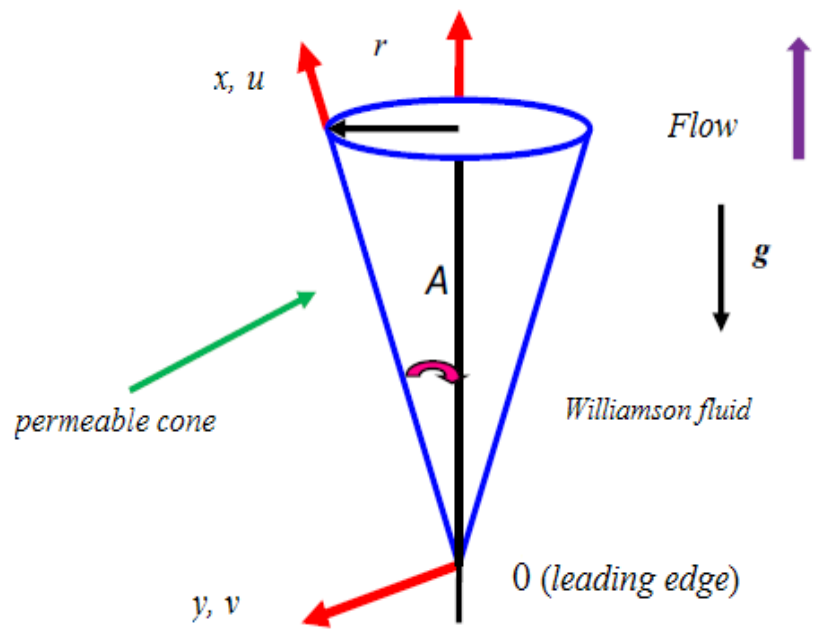

Fig. 1 Magnetohydrodynamic non-Newtonian heat transfer from a vertical permeable cone

The two-dimensional mass, momentum and energy boundary layer equations governing the flow in an $(x, y)$ coordinate system may be shown to take the form:

$$
\begin{aligned}
\frac{\partial(r u)}{\partial x}+\frac{\partial(r v)}{\partial y} & =0 \\
u \frac{\partial u}{\partial x}+v \frac{\partial u}{\partial y}= & v \frac{\partial^{2} u}{\partial y^{2}}+\sqrt{2} v \Gamma \frac{\partial u}{\partial y} \frac{\partial^{2} u}{\partial y^{2}} \\
& +g \beta\left(T-T_{\infty}\right) \cos A-\frac{\sigma B_{0}^{2}}{\rho} u
\end{aligned}
$$




$$
u \frac{\partial T}{\partial x}+v \frac{\partial T}{\partial y}=\alpha \frac{\partial^{2} T}{\partial y^{2}}
$$

The boundary conditions for the considered flow with velocity and thermal slip are:

At $y=0, u=N_{0} \frac{\partial u}{\partial y}, v=0, T=T_{w}+K_{0} \frac{\partial T}{\partial y}$

As $y \rightarrow \infty, u \rightarrow 0, v \rightarrow 0, T \rightarrow T_{\infty}$

Here $N_{0}$ is the velocity slip factor, $K_{0}$ is the thermal slip factor and $T_{\infty}$ is the free stream temperature. For $N_{0}=0=K_{0}$, one can recover the no-slip case. The stream function $\psi$ is defined by $r u=\frac{\partial \psi}{\partial y}$ and $r v=-\frac{\partial \psi}{\partial x}$, and therefore, the continuity equation is automatically satisfied. In order to write the governing equations and the boundary conditions in dimensionless form, the following non-dimensional quantities are introduced:

$$
\begin{gathered}
\xi=\frac{V_{0} x}{v G r^{1 / 4}}, \eta=\frac{y}{x}(G r)^{1 / 4}, \psi=v(G r)^{1 / 4}\left(f(\xi, \eta)+\frac{\xi}{2}\right) \\
\theta(\xi, \eta)=\frac{T-T_{\infty}}{T_{w}-T_{\infty}}, G r_{x}=\frac{g \beta_{T}\left(T_{w}-T_{\infty}\right) x^{3} \cos \mathrm{A}}{4 v^{2}}, M=\frac{\sigma B_{0}^{2} x^{2}}{\rho v G r^{1 / 2}}
\end{gathered}
$$

The emerging momentum and heat (energy) conservation equations in dimensionless from assume the following form:

$$
\begin{aligned}
& f^{\prime \prime \prime}+\frac{7}{4} f f^{\prime \prime}-\frac{1}{2} f^{\prime^{2}}+W e f^{\prime \prime} f^{\prime \prime \prime}+\theta-M f^{\prime} \\
& =\frac{7}{4} \xi\left(f^{\prime} \frac{\partial f^{\prime}}{\partial \xi}-f^{\prime \prime} \frac{\partial f}{\partial \xi}\right) \\
& \frac{\theta^{\prime \prime}}{\operatorname{Pr}}+\frac{7}{4} f \theta^{\prime}=\frac{7}{4} \xi\left(f^{\prime} \frac{\partial \theta}{\partial \xi}-\theta^{\prime} \frac{\partial f}{\partial \xi}\right)
\end{aligned}
$$

The transformed dimensionless boundary conditions are reduced to:

At $\eta=0, f=0, f^{\prime}=S_{f} f^{\prime \prime}(0), \theta=1+S_{T} \theta^{\prime}(0)$

As $\eta \rightarrow \infty, f^{\prime} \rightarrow 0, \theta \rightarrow 0$

The skin-friction coefficient (cone surface shear stress) and the local Nusselt number (cone surface heat transfer rate) can be defined, respectively, using the transformations described above with the following expressions:

$$
\begin{aligned}
& \frac{1}{2} G r^{-3 / 4} C_{f}=f^{\prime \prime}(\xi, 0)+\frac{W e}{2}\left(f^{\prime \prime}(\xi, 0)\right)^{2} \\
& G r^{-1 / 4} N u=-\theta^{\prime}(\xi, 0)
\end{aligned}
$$

All parameters are defined in the nomenclature.

\section{COMPUTATIONAL SOLUTION WITH KELLER BOX IMPLICT METHOD}

The transformed, nonlinear, multi-physical boundary value problem defined by Eqns. (14) - (16) can be solved via a number of numerical schemes. Here we implement a popular, second order accurate implicit finite difference method originally developed by Keller (1976). Recent studies featuring this method in the context of Magnetohydrodynamic and rheological flows include Sajid et al. (2016) who studied Ferro fluid flows in curved conduits, Gaffar et al. (2016) who investigated hydromagnetic tangent hyperbolic non-Newtonian convection from a cone and convective boundary layer flows by Rao et al. (2017). In the Keller box scheme, the multi-degree, multi-order coupled partial differential equations defined in (14) and (15) are first reduced to a system of first order equations. These equations are then discretized with the finite difference approximations with appropriate step lengths in each coordinate direction. Introducing the new variables:

$$
\begin{aligned}
& u(x, y)=f^{\prime}, v(x, y)=f^{\prime \prime}, s(x, y)=\theta \\
& f^{\prime}=u \\
& u^{\prime}=v \\
& \theta^{\prime}=t
\end{aligned}
$$

Eqns. (14) - (15) reduce then to the form:

$$
\begin{aligned}
& v^{\prime}+\frac{7}{4} f v+W e v v^{\prime}-\frac{1}{2} u^{2}+s-M u=\frac{7}{4} \xi\left(u \frac{\partial u}{\partial \xi}-v \frac{\partial f}{\partial \xi}\right) \\
& \frac{t^{\prime}}{\operatorname{Pr}}+\frac{7}{4} f t=\frac{7}{4} \xi\left(u \frac{\partial s}{\partial \xi}-t \frac{\partial f}{\partial \xi}\right)
\end{aligned}
$$

where primes denote differentiation with respect to $\eta$.In terms of the dependent variables, the boundary conditions (16) become:

$$
\begin{aligned}
& \text { At } \eta=0, f=0, f^{\prime}=S_{f} f^{\prime \prime}(0), \theta=1+S_{T} \theta^{\prime}(0) \\
& \text { As } \eta \rightarrow \infty, f^{\prime} \rightarrow 0, \theta \rightarrow 0
\end{aligned}
$$

A two-dimensional computational mesh (grid) is imposed on the $\xi-\eta$ plane as shown in Fig.2. The stepping process is defined by:

$$
\begin{aligned}
& \eta_{0}=0, \eta_{j}=\eta_{j-1}+h_{j}, j=1,2, \ldots, J, \eta_{J} \equiv \eta_{\infty} \\
& \xi^{0}=0, \xi^{n}=\xi^{n-1}+k_{n}, n=1,2, \ldots, N
\end{aligned}
$$

where $k_{n}$ and $h_{j}$ denote the step distances in the $\xi$ and $\eta$ directions respectively.

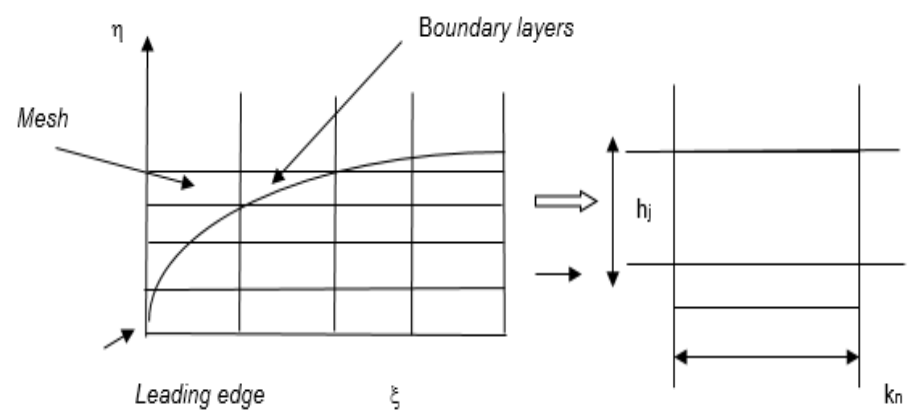

Fig. 2 Keller Box element and boundary layer mesh

If $g_{j}^{n}$ denotes the value of any variable at $\left(\eta_{j}, \xi^{n}\right)$, then the variables and derivatives of Equations. (20) - (24) at $\left(\eta_{j-1 / 2}, \xi^{n-1 / 2}\right)$ are replaced by:

$$
\begin{aligned}
& g_{j-1 / 2}^{n-1 / 2}=\frac{1}{4}\left(g_{j}^{n}+g_{j-1}^{n}+g_{j}^{n-1}+g_{j-1}^{n-1}\right) \\
& \left(\frac{\partial g}{\partial \eta}\right)_{j-1 / 2}^{n-1 / 2}=\frac{1}{2 h_{j}}\left(g_{j}^{n}-g_{j-1}^{n}+g_{j}^{n-1}-g_{j-1}^{n-1}\right)
\end{aligned}
$$




$$
\left(\frac{\partial g}{\partial \xi}\right)_{j-1 / 2}^{n-1 / 2}=\frac{1}{2 k^{n}}\left(g_{j}^{n}-g_{j-1}^{n}+g_{j}^{n-1}-g_{j-1}^{n-1}\right)
$$

The finite-difference approximation of equations. (20) - (24) for the mid-point $\left(\eta_{j-1 / 2}, \xi^{n}\right)$ assume the form given below:

$h_{j}^{-1}\left(f_{j}^{n}-f_{j-1}^{n}\right)=u_{j-1 / 2}^{n}$

$h_{j}^{-1}\left(u_{j}^{n}-u_{j-1}^{n}\right)=v_{j-1 / 2}^{n}$

$h_{j}^{-1}\left(s_{j}^{n}-s_{j-1}^{n}\right)=t_{j-1 / 2}^{n}$

$\left(v_{j}-v_{j-1}\right)+\frac{W e}{2}\left(v_{j}+v_{j-1}\right)\left(v_{j}-v_{j-1}\right)$

$+(1+\alpha) \frac{7 h_{j}}{16}\left[\left(f_{j}+f_{j-1}\right)\left(v_{j}+v_{j-1}\right)\right]$

$-\frac{(2+7 \alpha) h_{j}}{16}\left(u_{j}+u_{j-1}\right)^{2}-\frac{M h_{j}}{2}\left(u_{j}+u_{j-1}\right)$

$+\frac{h_{j}}{2}\left(s_{j}+s_{j-1}\right)-\frac{7 \alpha h_{j}}{8} f_{j-1 / 2}^{n-1}\left(v_{j}+v_{j-1}\right)$

$+\frac{7 \alpha h_{j}}{8} v_{j-1 / 2}^{n-1}\left(f_{j}+f_{j-1}\right)=\left[R_{1}\right]_{j-1 / 2}^{n-1}$

$\frac{1}{\operatorname{Pr}}\left(t_{j}-t_{j-1}\right)+(1+\alpha) \frac{7 h_{j}}{16}\left[\left(f_{j}+f_{j-1}\right)\left(t_{j}+t_{j-1}\right)\right]$

$-\frac{7 \alpha h_{j}}{16}\left[\left(u_{j}+u_{j-1}\right)\left(s_{j}+s_{j-1}\right)\right]+\frac{7 \alpha h_{j}}{8} s_{j-1 / 2}^{n-1}\left(u_{j}+u_{j-1}\right)$

$-\frac{7 \alpha h_{j}}{8} u_{j-1 / 2}^{n-1}\left(s_{j}+s_{j-1}\right)-\frac{7 \alpha h_{j}}{8} f_{j-1 / 2}^{n-1}\left(t_{j}+t_{j-1}\right)$

$+\frac{7 \alpha h_{j}}{8} t_{j-1 / 2}^{n-1}\left(f_{j}+f_{j-1}\right)=\left[R_{2}\right]_{j-1 / 2}^{n-1}$

Here the following abbreviations apply:

$\alpha=\frac{\xi^{n-1 / 2}}{k_{n}}$

$\left[R_{1}\right]_{j-1 / 2}^{n-1}=-h_{j}\left[\begin{array}{l}\left(\frac{v_{j}-v_{j-1}}{h_{j}}\right)+W_{e} v_{j-1} v_{j-1 / 2}^{\prime}+\left(\frac{7 \alpha-2}{4}\right)\left(u_{j-1 / 2}\right)^{2} \\ +\frac{7}{4}(1-\alpha)\left(f_{j-1 / 2} v_{j-1 / 2}\right)+\left(s_{j-1 / 2}\right)-M\left(u_{j-1 / 2}\right)\end{array}\right]$

$\left[R_{2}\right]_{j-1 / 2}^{n-1}=-h_{j}\left[\begin{array}{l}\frac{1}{\operatorname{Pr}}\left(\frac{t_{j}-t_{j-1}}{h_{j}}\right)+\frac{7}{4} \alpha\left(u_{j-1 / 2} s_{j-1 / 2}\right) \\ +\frac{7}{4}(1-\alpha)\left(f_{j-1 / 2} t_{j-1 / 2}\right)\end{array}\right]$

The boundary conditions take the form:

$f_{0}^{n}=u_{0}^{n}=0, \theta_{0}^{n}=1, u_{J}^{n}=0, v_{J}^{n}=0, \theta_{J}^{n}=0$
The emerging non-linear system of algebraic equations is linearized by means of Newton's method and then solved by the block-elimination method. The accuracy of computations is influenced by the number of mesh points in both directions. After experimenting with various grid sizes in the $\eta$-direction (radial coordinate) a larger number of mesh points are selected whereas in the $\xi$ direction (tangential coordinate) significantly less mesh points are utilized. $\eta_{\max }$ has been set at 10 and this defines a sufficiently large value at which the prescribed boundary conditions are satisfied. $\xi_{\max }$ is set at 1.0 for this flow domain. Mesh independence is therefore achieved in the present computations. The computer program of the algorithm is executed in MATLAB running on a PC.

\section{VALIDATION OF KELLER BOX SOLUTIONS}

The present Keller box solutions have been validated for the special case of non-magnetic $(M=0)$ Newtonian flow $(W e=0)$ in the absence of thermal and partial slip $\left(S_{f}=S_{T}=0\right)$. This case was considered earlier by Alam et al. (2007). Furthermore, when nonuniform surface temperature is ignored in the model of Hossain and Paul (2001) in addition to prescribing $M=W e=S_{f}=S_{T}=0$ in the present model, it is also possible to make a comparison as the momentum equation and boundary conditions assume the following reduced form:

$$
f^{\prime \prime \prime}+\frac{7}{4} f f^{\prime \prime}-\frac{1}{2} f^{\prime 2}+\theta=\xi\left(f^{\prime} \frac{\partial f^{\prime}}{\partial \xi}-f^{\prime \prime} \frac{\partial f}{\partial \xi}\right)
$$

At $\eta=0 ; f=0 ; f^{\prime}=0, \theta=1$

At $\eta \rightarrow \infty: f^{\prime} \rightarrow 0 ; \theta \rightarrow 0$.

The energy equation (15) is identical to that considered in Alam et al. (2007). The comparison of solutions is documented in Table 1. Excellent correlation is achieved and confidence in the present solutions is therefore justifiably high.

Table. 1 Comparison values of $f^{\prime \prime}(\xi, 0)$ and $-\theta^{\prime}(\xi, 0)$ for various values of $\xi$.

\begin{tabular}{|c|c|c|c|c|}
\hline \multirow{2}{*}{$\xi$} & \multicolumn{2}{|c|}{$f^{\prime \prime}(\xi, 0)$} & \multicolumn{2}{c|}{$-\theta^{\prime}(\xi, 0)$} \\
\cline { 2 - 5 } & $\begin{array}{c}\text { Alam et al. } \\
(2007)\end{array}$ & $\begin{array}{c}\text { Present } \\
\text { Solutions }\end{array}$ & $\begin{array}{c}\text { Alam et al. } \\
(2007)\end{array}$ & $\begin{array}{c}\text { Present } \\
\text { Solutions }\end{array}$ \\
\hline 0 & 0.891936 & 0.891940 & 0.420508 & 0.420502 \\
\hline 0.5 & 0.896407 & 0.896403 & 0.620748 & 0.620744 \\
\hline 1.0 & 0.856963 & 0.856965 & 0.848025 & 0.848030 \\
\hline 1.5 & 0.779210 & 0.779211 & 1.129365 & 1.129369 \\
\hline 2.0 & 0.674111 & 0.674110 & 1.441742 & 1.441747 \\
\hline 3.0 & 0.434152 & 0.434151 & 2.202662 & 2.202661 \\
\hline
\end{tabular}

\section{RESULTS AND DISCUSSION}

Extensive computations have been conducted using the Keller box code to study the influence of the key thermo-physical parameters on velocity, temperature, skin friction and Nusselt number. These are visualized in figs. 3a-b to 8a-b and tables 2-3.

Figs 3a-b illustrate the influence of Weissenberg number $(\mathrm{We})$ on velocity and temperature profiles. We arises only in the momentum eqn. (14) in the mixed derivative Wef ' $f^{\prime \prime \prime}$. Weissenberg number (We) measures the relative effects of viscosity to elasticity. Weissenberg number of zero corresponds to a purely(3ggwtonian fluid, and infinite 
Weissenberg number corresponds to a purely elastic solid. Intermediate values correlate quite well with actual polymeric viscoelastic properties. With increasing $W e$, there is a general increase through the boundary layer in velocity magnitudes. The boundary layer flow is therefore accelerated as viscous effects are depleted since resistance to the flow is reduced.

The momentum boundary layer is therefore depleted with greater Weissenberg number. We note that in fig. 3a the magnetic body force parameter, $M$, is set at unity implying that the Lorentzian magnetic drag and viscous hydrodynamic force are of the same magnitude. Fig. 3b shows that a consistent elevation is computed in temperature of the viscoelastic fluid with greater values of Weissenberg number, We. The acceleration in the flow aids in momentum development which also assists in thermal diffusion, leading to heating of the boundary layer. Thermal boundary layer thickness is therefore enhanced with increasing $W e$ values i.e. decreasing viscosity and increasing elastic effects. Effectively therefore Newtonian fluids (We $=0$ ) achieve lower velocities and temperatures than Williamson fluids. Similar trends have been reported by Hayat et al. (2016) and Khan and Khan (2014).

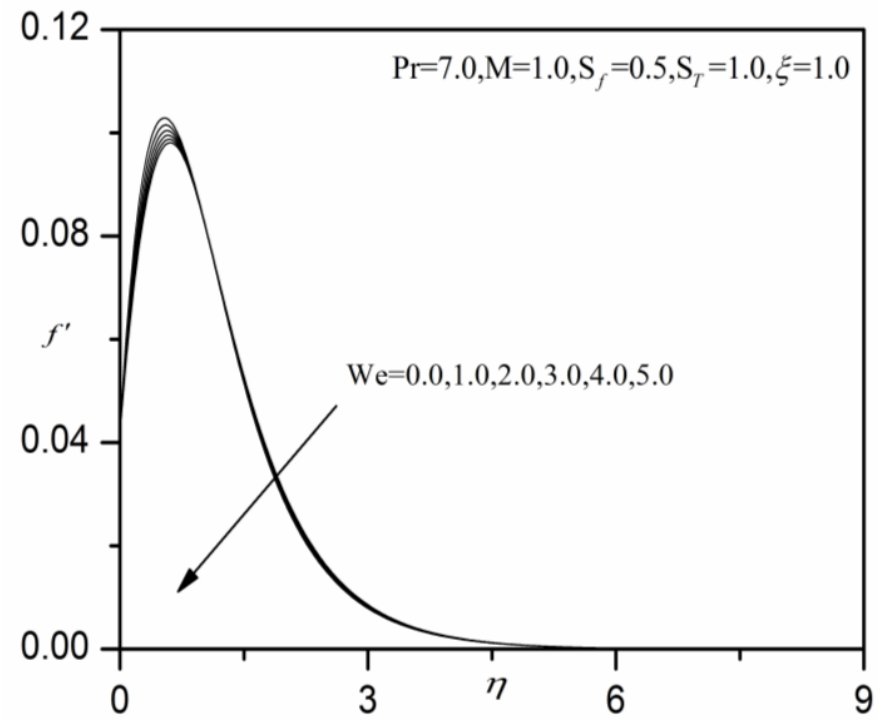

(a)

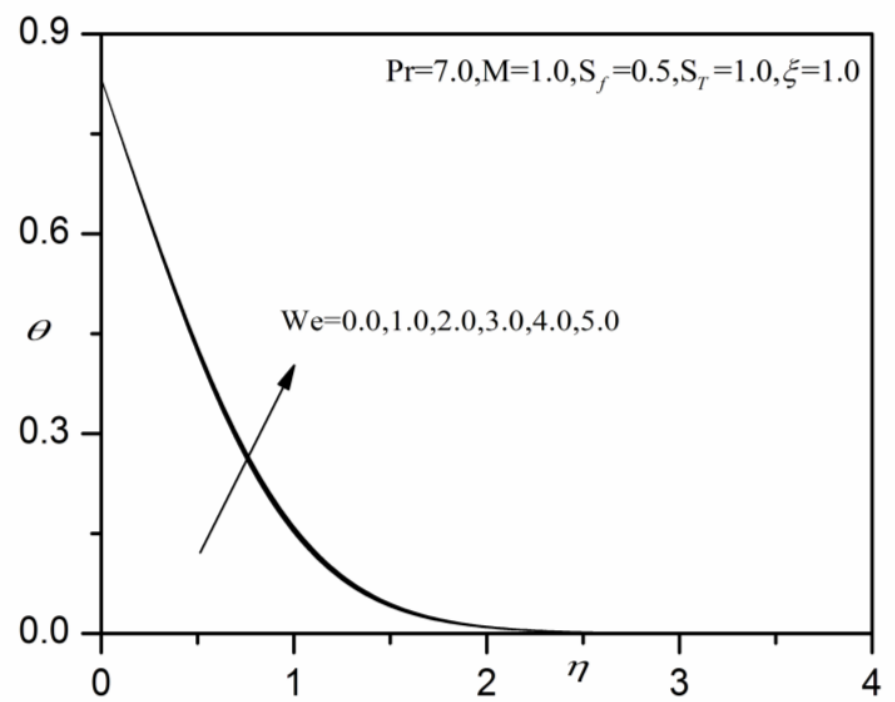

(b)

Fig. 3 Effect of We on (a) velocity profiles and (b) temperature profiles
Figs. 4a-b depict the evolution in velocity and temperature characteristics with transverse coordinate i.e. normal to the vertical cone surface for various Prandtl numbers, Pr. Relatively high values of $\mathrm{Pr}$ are considered since these physically correspond to industrial polymers (2004). Prandtl number embodies the ratio of momentum diffusivity to thermal diffusivity in the boundary layer regime. It also represents the ratio of the product of specific heat capacity and dynamic viscosity, to the fluid thermal conductivity. For polymers momentum diffusion rate greatly exceeds thermal diffusion rate. The low values of thermal conductivity in most polymers also result in a high Prandtl number. With increasing $\operatorname{Pr}$ from 7 to 100 there is evidently a substantial deceleration in boundary layer flow i.e. a thickening in the momentum boundary layer (fig. 4a). The effect is most prominent close to the vertical cone surface. Also fig. $4 \mathrm{~b}$ shows that with greater Prandtl number the temperature values are strongly decreased throughout the boundary layer transverse to the vertical cone surface. Thermal boundary layer thickness is therefore significantly reduced. The asymptotically smooth profiles in the free stream (high $\eta$ values) confirm that an adequately large infinity boundary condition has been imposed in the Keller box numerical code.

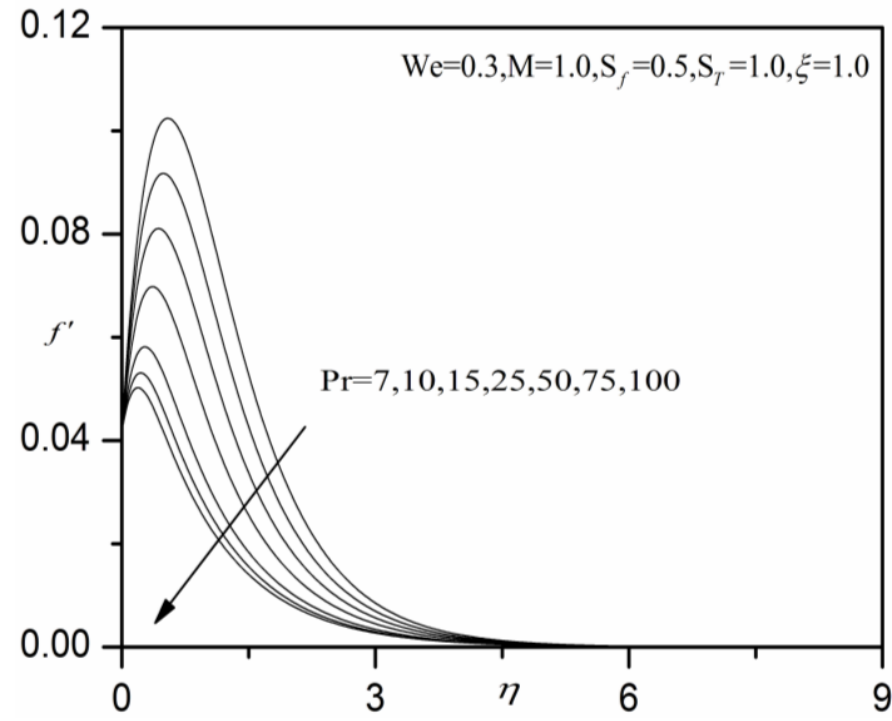

(a)

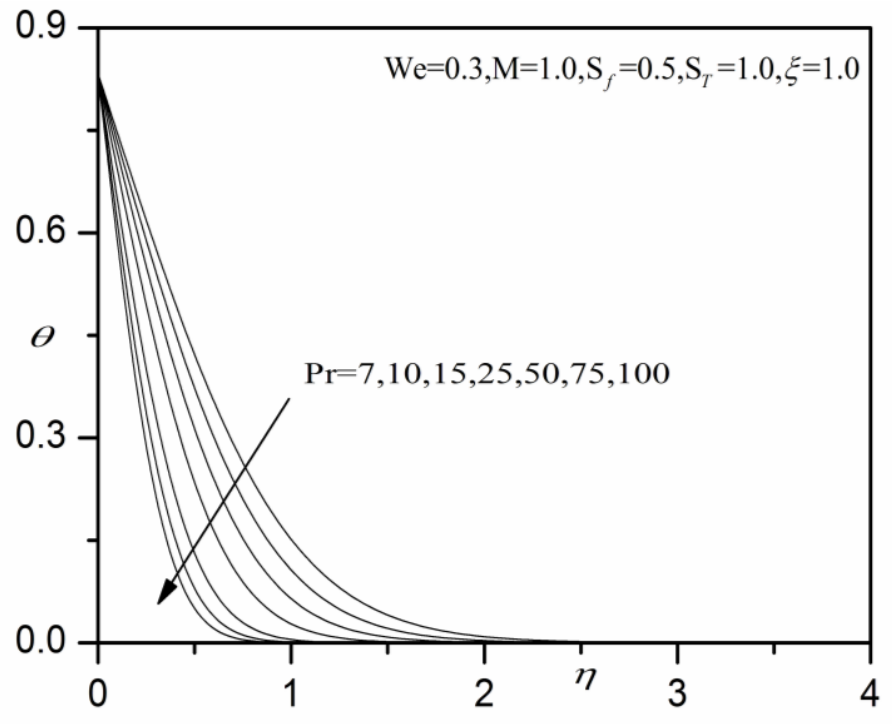

(b)

Fig. 4 Effect of $\operatorname{Pr}$ on (a) velocity profiles and (b) temperature profiles 
Figs. 5a-b present the evolution in velocity and temperature functions with a variation in magnetic body force parameter $(M)$. The radial magnetic field generates a transverse retarding body force. This decelerates the boundary layer flow and velocities are therefore reduced as observed in fig. 5a. The momentum development in the viscoelastic coating can therefore be controlled using a radial magnetic field. The effect is prominent throughout the boundary layer from the cone surface to the free stream. Momentum (hydrodynamic) boundary layer thickness is therefore increased with greater magnetic field. Fig. 5b shows that the temperature is strongly enhanced with greater magnetic parameter. The excess work expended in dragging the polymer against the action of the magnetic field is dissipated as thermal energy (heat). This energizes the boundary layer and increases thermal boundary layer thickness. Again the influence of magnetic field is sustained throughout the entire boundary layer domain. These results concur with other investigations of magnetic non-Newtonian heat transfer including Kasim et al. (2013) and Megahed (2010).

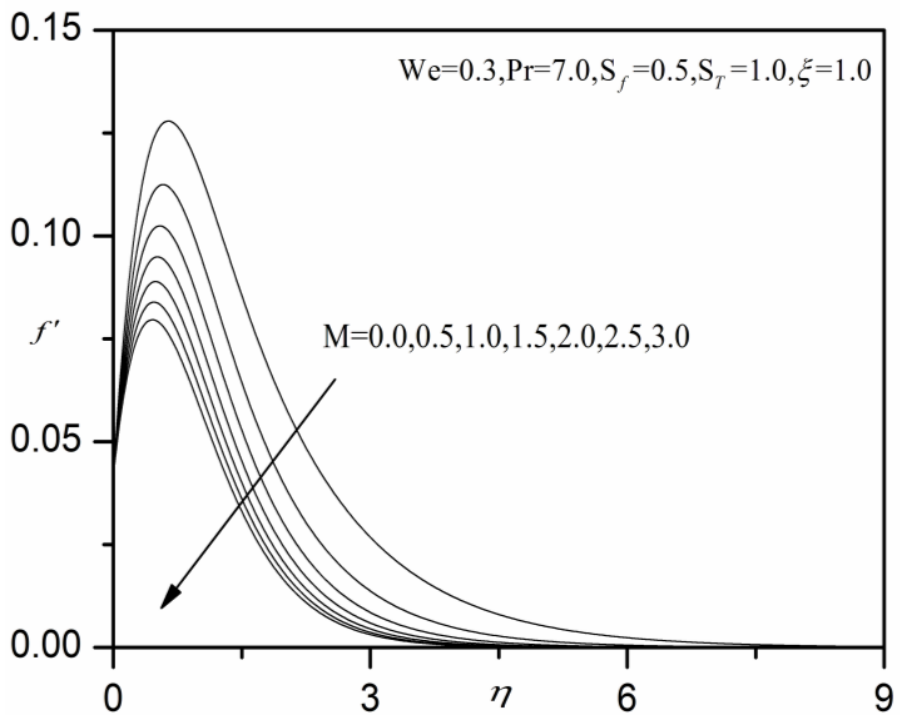

(a)

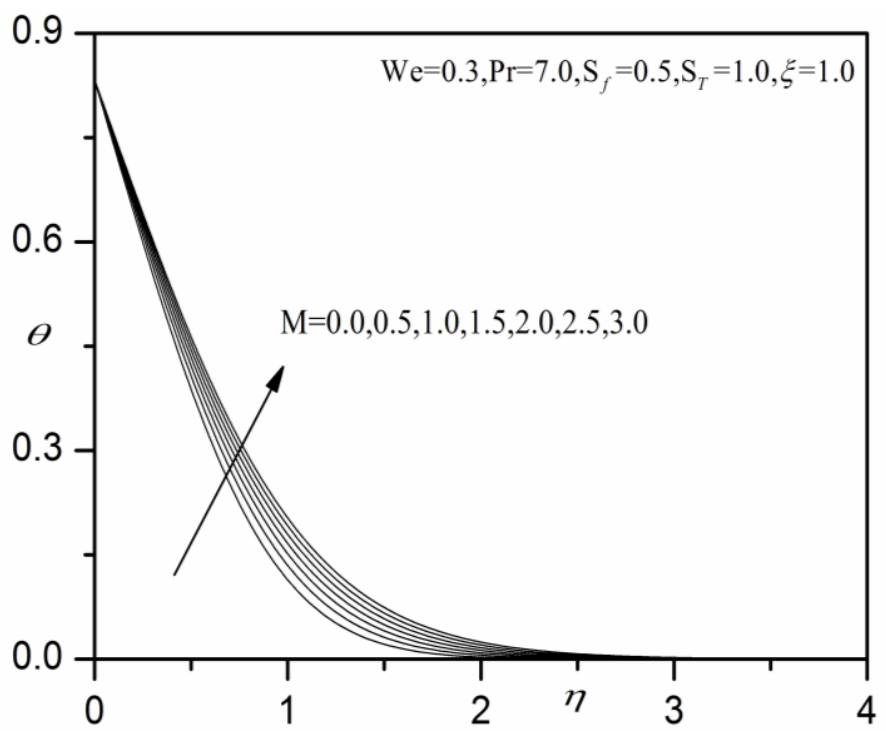

(b)

Fig. 5 Effect of $M$ on (a) velocity profiles and (b) temperature profiles

Figs. 6a-b illustrate the impact of the momentum (hydrodynamic) slip parameter $\left(S_{f}\right)$ on the velocity and temperature distributions. Near the cone surface there is a distinct elevation in velocity with greater momentum slip effect. $S_{f}$ features in the velocity wall boundary condition in eqn. (16) i.e. $f^{\prime}(0)=S_{f} f^{\prime \prime}(0)$. With increasing values of $S_{f}$ the polymer slips i.e. shears more easily against the cone surface. This boosts momentum in the boundary layer and accelerates the flow (fig. 6a). However, with progressive penetration into the boundary layer, this effect is reversed (as expected) and the flow is decelerated with greater momentum slip further from the cone surface.

The velocity slip effect is strongest at the cone surface $(\eta=$ 0). A similar observation has been made by Yarin and Graham (1998) and also by Jamil and Khan (2011). The momentum slip effect is prominent and substantially modifies the velocity growth structure. Temperature is conversely reduced consistently throughout the boundary layer with greater momentum slip. The viscoelastic polymer is therefore cooled with wall momentum slip and this reduces thermal boundary layer thickness. The implication is therefore that with an absence of velocity slip in mathematical models, temperature is overpredicted (the maximum value corresponds to $S_{f}=0$ ). It is therefore important in more realistic simulations of polymer coating dynamics to incorporate wall slip effects.

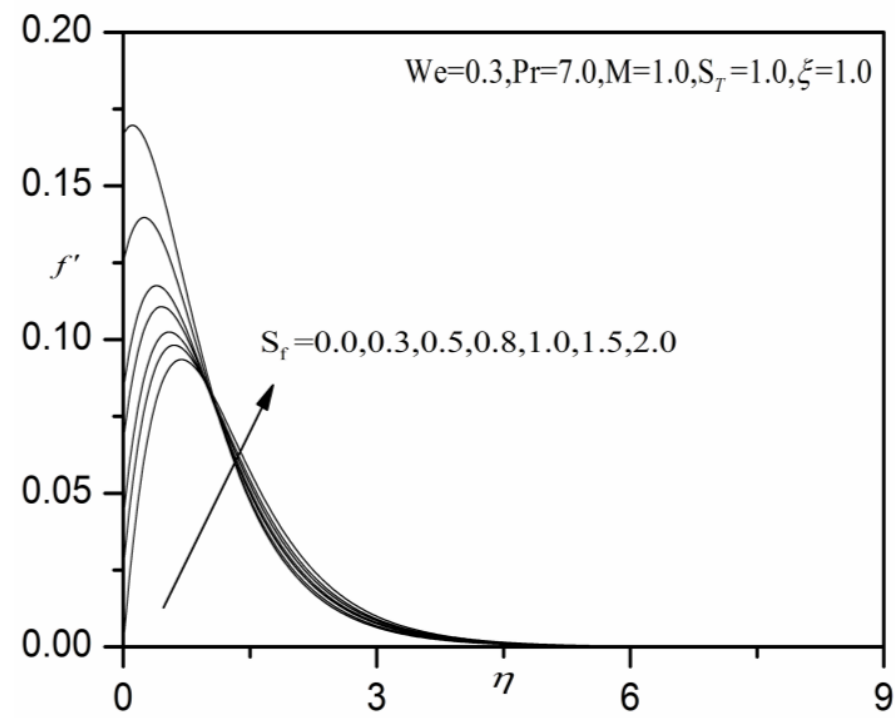

(a)

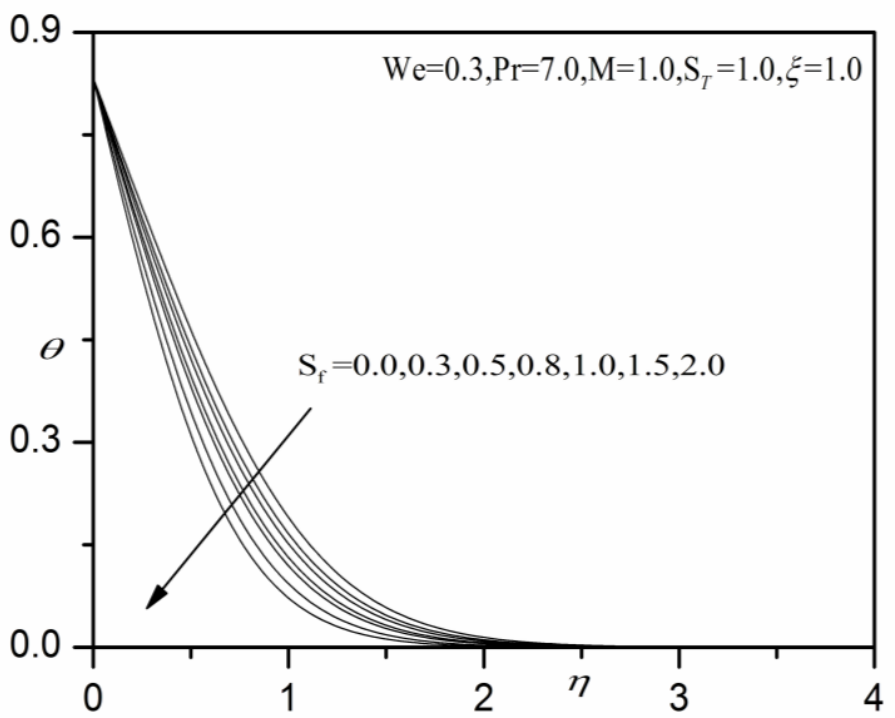

(b)

Fig. 6 Effect of $S_{f}$ on (a) velocity profiles and (b) temperature profiles

Figs. 7a-b present the response in velocity and temperature distributions to a modification in the thermal jump (slip) parameter $\left(S_{T}\right)$. A marked depletion in velocity (fig. 7a) accompanies an increase in 
thermal slip effect and this trend is sustained throughout the boundary layer. The thermal slip parameter indirectly influences the momentum field via coupling to the energy equation (thermal slip is only simulated in the wall thermal boundary condition in eqn. 16). With greater thermal slip, there is also a very profound depletion in temperature at the cone surface and in close proximity to it (fig. 7b). However, this effect weakens considerably with further distance from the cone surface and is effectively eliminated before reaching the free stream. Temperature profiles decay from a maximum at the cone surface to the free stream. All profiles converge at a large value of transverse coordinate, again showing that a sufficiently large infinity boundary condition has been utilized in the numerical computations. Again the absence of thermal slip achieves higher temperatures indicating that without this modification in the thermal boundary condition at the wall (cone surface) the temperature is over-predicted, which can be critical to heat treatment of polymeric coatings (2015).

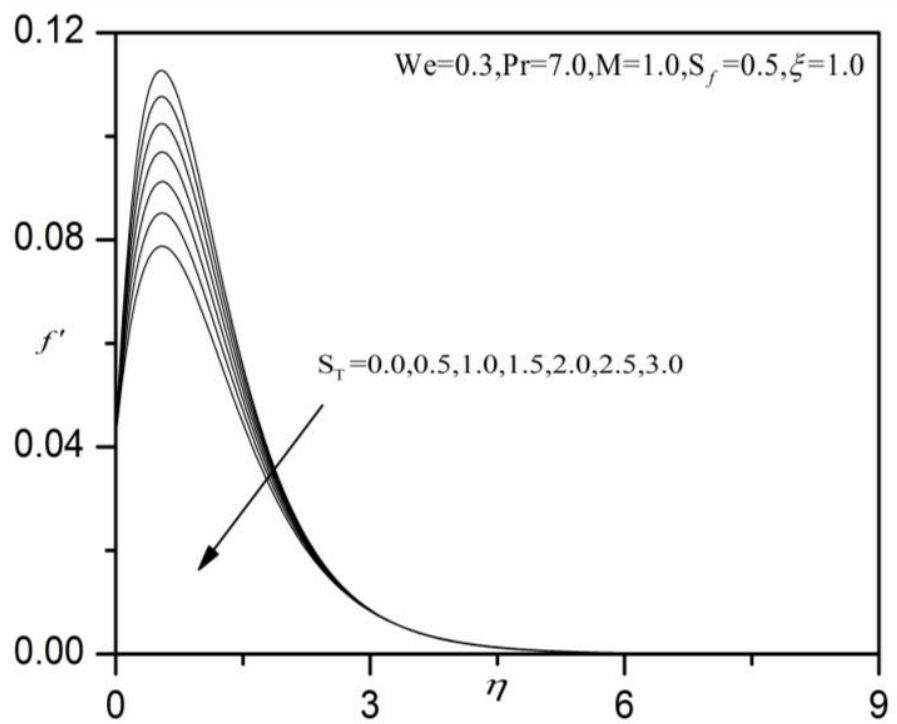

(a)

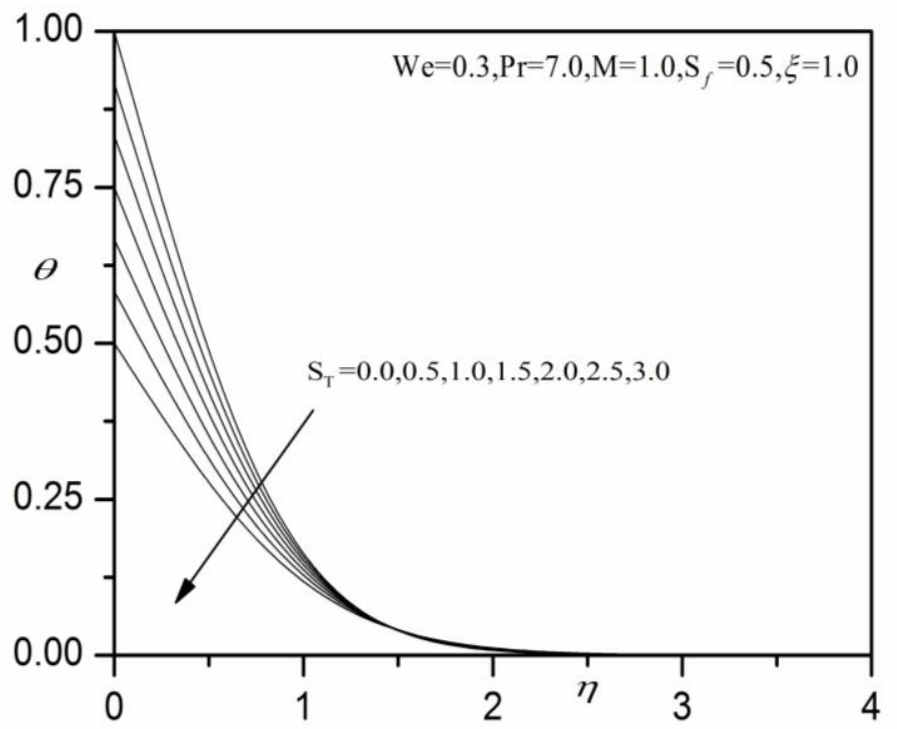

(b)

Fig. 7 Effect of $S_{T}$ on (a) velocity profiles and (b) temperature profiles

Figs. 8a-b illustrate the influence of the stream wise (tangential) coordinate, $\xi$, on the velocity and temperature distributions. A weak deceleration in the boundary layer flow is experienced with greater $\xi$, as shown in fig. 8a. Momentum boundary layer thickness is therefore increased marginally with $\xi$ values. Conversely a weak enhancement in temperature is computed in fig. 8b, with increasing $\xi$ values. Thermal boundary layer thickness is increased therefore as we progress from the lower stagnation point on the cone surface around the cone periphery upwards.

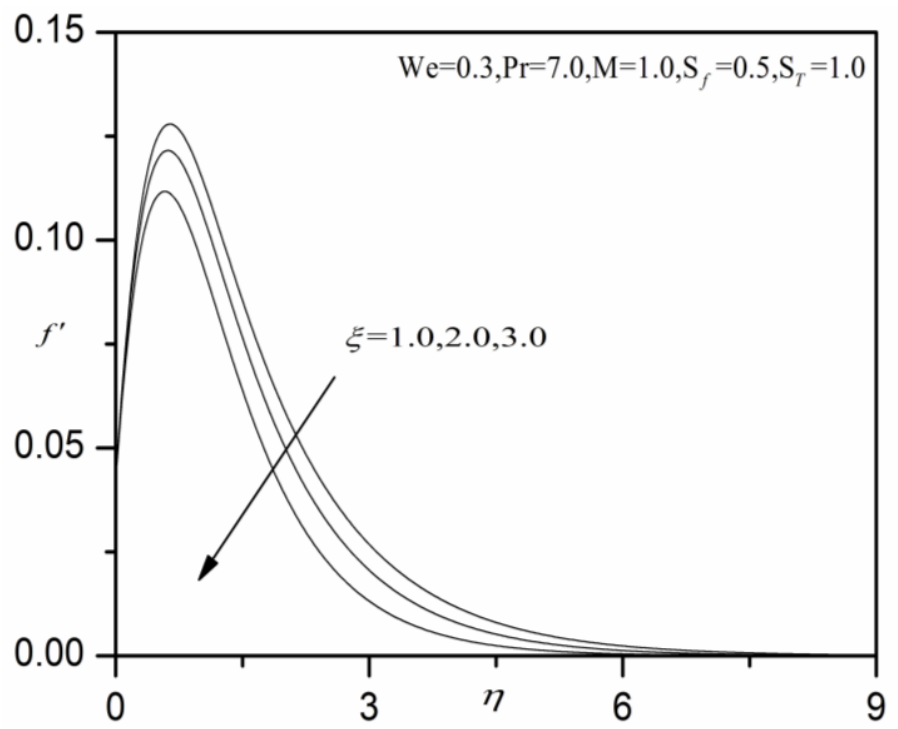

(a)

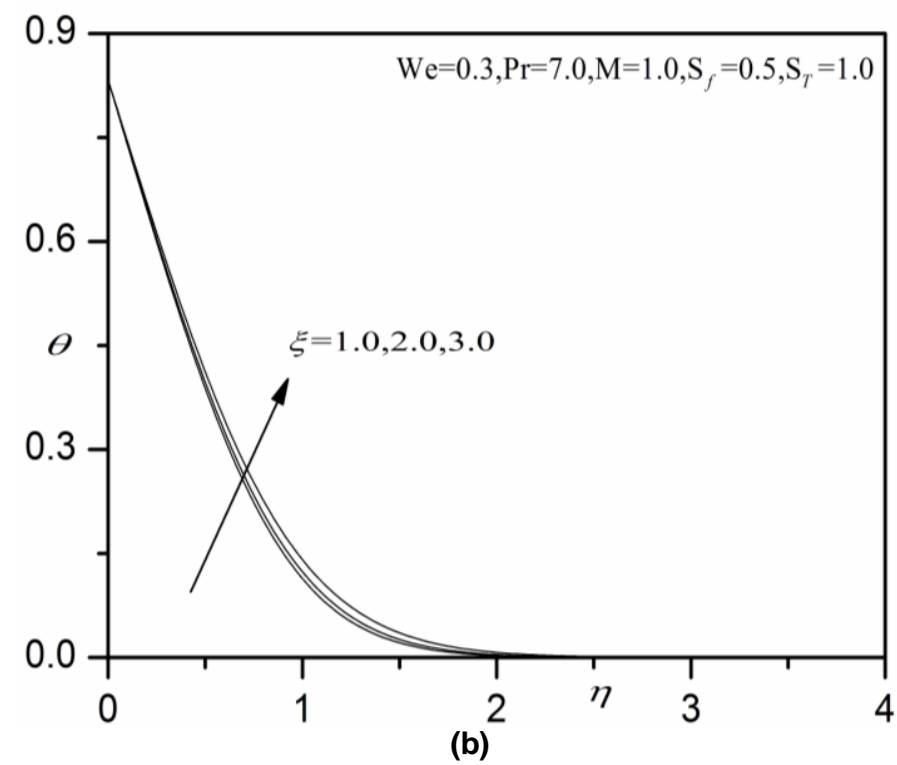

Fig. 8 Effect of $\xi$ on (a) velocity profiles and (b) temperature profiles

Table 2-3. Illustrate the skin friction and Nusselt number distributions with various values of momentum slip parameter $\left(S_{f}\right)$ and thermal slip effect $\left(S_{T}\right)$. A marked depreciation in skin friction is observed with greater momentum slip. Conversely a strong elevation in Nusselt number is generated with greater momentum slip effect. The momentum slip effect is consistent for all values of stream wise parameter $(\xi)$. The influence of momentum (hydrodynamic) slip is nontrivial and demonstrates that a sizeable modification in surface thermofluid characteristics is induced with slip and indeed that the methodology employed to simulate it quite realistically simulates real macroscopic effects of certain molecular phenomena at polymer/solid interfaces. Both skin friction and Nusselt number are strongly reduced with an increase thermal slip $\left(S_{T}\right)$. The boundary layer is therefore decelerated and heated with stronger thermal slip. With thermal slip absent therefore the skin friction is maximized at the cone surface. The inclusion of thermal slip, which is encountered in various slippy 
polymer flows, is therefore important in more physically realistic simulations.

Table. 2 Values of $f^{\prime \prime}(\xi, 0)$ for different $S_{f}, S_{T}$ and $\xi$

\begin{tabular}{|c|c|c|c|c|}
\hline \multirow{2}{*}{$S_{f}$} & \multirow{2}{*}{$S_{T}$} & \multicolumn{3}{|c|}{$f^{\prime \prime}(\xi, 0)$} \\
\hline & & $\xi=1.0$ & $\xi=2.0$ & $\xi=3.0$ \\
\hline 0.0 & \multirow{7}{*}{1.0} & 0.3473 & 0.4415 & 0.4506 \\
\hline 0.1 & & 0.3376 & 0.4280 & 0.4344 \\
\hline 0.2 & & 0.3280 & 0.4144 & 0.4182 \\
\hline 0.3 & & 0.3183 & 0.4009 & 0.4020 \\
\hline 0.5 & & 0.2989 & 0.3738 & 0.3694 \\
\hline 0.8 & & 0.2699 & 0.3330 & 0.3204 \\
\hline 1.0 & & 0.2504 & 0.3058 & 0.2876 \\
\hline \multirow{6}{*}{0.5} & 0.0 & 0.3382 & 0.4241 & 0.4218 \\
\hline & 0.5 & 0.3187 & 0.3991 & 0.3957 \\
\hline & 1.5 & 0.2790 & 0.3481 & 0.3427 \\
\hline & 2.0 & 0.2587 & 0.3222 & 0.3157 \\
\hline & 2.5 & 0.2381 & 0.2958 & 0.2884 \\
\hline & 3.0 & 0.2172 & 0.2690 & 0.2606 \\
\hline
\end{tabular}

Table. 3 Values of $-\theta^{\prime}(\xi, 0)$ for different $S_{f}, S_{T}$ and $\xi$

\begin{tabular}{|c|c|c|c|c|}
\hline \multirow{2}{*}{$S_{f}$} & \multirow{2}{*}{$S_{T}$} & \multicolumn{3}{|c|}{$-\theta^{\prime}(\xi, 0)$} \\
\hline & & $\xi=1.0$ & $\xi=2.0$ & $\xi=3.0$ \\
\hline 0.0 & \multirow{7}{*}{1.0} & 0.6521 & 0.5687 & 0.4466 \\
\hline 0.1 & & 0.6641 & 0.5795 & 0.4554 \\
\hline 0.2 & & 0.6761 & 0.5904 & 0.4638 \\
\hline 0.3 & & 0.6883 & 0.6013 & 0.4727 \\
\hline 0.5 & & 0.7125 & 0.6234 & 0.4904 \\
\hline 0.8 & & 0.7492 & 0.6563 & 0.5173 \\
\hline 1.0 & & 0.7726 & 0.6786 & 0.5351 \\
\hline \multirow{6}{*}{0.5} & 0.0 & 0.8421 & 0.7374 & 0.5814 \\
\hline & 0.5 & 0.7767 & 0.6798 & 0.5355 \\
\hline & 1.5 & 0.6494 & 0.5678 & 0.4462 \\
\hline & 2.0 & 0.5875 & 0.5134 & 0.4029 \\
\hline & 2.5 & 0.5272 & 0.4601 & 0.3607 \\
\hline & 3.0 & 0.4680 & 0.4080 & 0.3194 \\
\hline
\end{tabular}

Tables 4-5, presents the influence of magnetic parameter $(M)$ and Weissenberg number (We), on skin friction and Nusselt number, along with a variation in the Prandtl number $(\mathrm{Pr})$. A significant depletion is caused in skin friction with greater magnetic field, which corresponds to a retardation of the boundary layer flow. The maximum skin friction therefore is achieved only in the absence of a radial magnetic field i.e. $M=0$. For $M<1$, the magnetic body force is exceeded by the viscous hydrodynamic force in the regime. For $M>1$ the contrary is the case. The reduction in Nusselt number with greater $M$ values implies that the transfer of heat from the boundary layer to the wall (cone surface) is reduced. This physically indicates therefore that greater heat is conveyed away from the cone surface to the fluid which explains the higher temperatures associated with strong magnetic field in the earlier computations. Magnetic field is therefore a potent mechanism for controlling thermal and velocity characteristics in electrically-conducting polymer dynamics. With progressively greater We values the elasticity in the polymer is increased. This aids in momentum development and accelerates the boundary layer flow. The Weissenberg number indicates the degree of anisotropy or orientation generated by the deformation, and is appropriate to describe flows with a constant stretch history, and therefore appropriate for polymers. A strong reduction in Nusselt number arises with an elevation in Weissenberg number i.e. heat is transferred from the cone surface to the boundary layer, wherein temperature (and thermal boundary layer thickness) are found to be enhanced with Wiessenberg number. The cone surface is therefore effectively cooled with greater Weissenberg numbers. Increasing Prandtl number $(\mathrm{Pr})$ reduces skin friction but enhances heat transfer rate (Nusselt number) and furthermore provide benchmarks against which other researchers may validate extensions of the present model.

Table. 4 Values of $f^{\prime \prime}(\xi, 0)$ for different values of We, $M$ and $\operatorname{Pr}$

\begin{tabular}{|c|c|c|c|c|c|}
\hline \multirow{2}{*}{ We } & \multirow{2}{*}{$M$} & \multicolumn{4}{|c|}{$f^{\prime \prime}(\xi, 0)$} \\
\hline & & $\operatorname{Pr}=7$ & $\operatorname{Pr}=10$ & $\operatorname{Pr}=20$ & $\operatorname{Pr}=25$ \\
\hline 0.0 & \multirow{6}{*}{1.0} & 0.2960 & 0.2730 & 0.2294 & 0.2157 \\
\hline 0.5 & & 0.3008 & 0.2769 & 0.2316 & 0.2176 \\
\hline 1.0 & & 0.3049 & 0.2803 & 0.2341 & 0.2198 \\
\hline 2.0 & & 0.3122 & 0.2864 & 0.2382 & 0.2234 \\
\hline 3.0 & & 0.3185 & 0.2916 & 0.2417 & 0.2265 \\
\hline 4.0 & & 0.3240 & 0.2964 & 0.2449 & 0.2294 \\
\hline \multirow{6}{*}{0.3} & 0.0 & 0.3760 & 0.3444 & 0.2870 & 0.2698 \\
\hline & 0.5 & 0.3302 & 0.3029 & 0.2529 & 0.2376 \\
\hline & 1.0 & 0.2989 & 0.2753 & 0.2308 & 0.2170 \\
\hline & 2.0 & 0.2538 & 0.2352 & 0.1988 & 0.1872 \\
\hline & 3.0 & 0.2203 & 0.2052 & 0.1745 & 0.1645 \\
\hline & 4.0 & 0.1936 & 0.1809 & 0.1546 & 0.1457 \\
\hline
\end{tabular}

Table. 5 Values of $-\theta^{\prime}(\xi, 0)$ for different values of $W e, M$ and $\operatorname{Pr}$

\begin{tabular}{|c|c|c|c|c|c|}
\hline \multirow{2}{*}{ We } & \multirow{2}{*}{$M$} & \multicolumn{4}{|c|}{$-\theta^{\prime}(\xi, 0)$} \\
\hline & & $\operatorname{Pr}=7$ & $\operatorname{Pr}=10$ & $\operatorname{Pr}=20$ & $\operatorname{Pr}=25$ \\
\hline 0.0 & \multirow{6}{*}{1.0} & 0.7145 & 0.8098 & 1.0370 & 1.1239 \\
\hline 0.5 & & 0.7104 & 0.8063 & 1.0322 & 1.1190 \\
\hline 1.0 & & 0.7072 & 0.8028 & 1.0289 & 1.1158 \\
\hline 2.0 & & 0.7012 & 0.7966 & 1.0226 & 1.1095 \\
\hline 3.0 & & 0.6961 & 0.7912 & 1.0168 & 1.1036 \\
\hline 4.0 & & 0.6917 & 0.7865 & 1.0117 & 1.0986 \\
\hline \multirow{6}{*}{0.3} & 0.0 & 0.8013 & 0.9019 & 1.1364 & 1.2267 \\
\hline & 0.5 & 0.7497 & 0.8463 & 1.0747 & 1.1628 \\
\hline & 1.0 & 0.7125 & 0.8089 & 1.0330 & 1.1213 \\
\hline & 2.0 & 0.6568 & 0.7512 & 0.9736 & 1.0593 \\
\hline & 3.0 & 0.6144 & 0.7072 & 0.9277 & 1.0122 \\
\hline & 4.0 & 0.5799 & 0.6710 & 0.8902 & 0.9735 \\
\hline
\end{tabular}

\section{CONCLUSIONS}

Motivated by applications in thermal processing of magnetic polymers in coating systems, a mathematical model has been developed for the magneto-hydrodynamic flow and heat transfer in an electroconductive viscoelastic Williamson fluid from a vertical permeable cone body under radial magnetic field. To simulate slippery polymer 
interfacial effects, both thermal and momentum slip have been incorporated into the model. The normalized, nonlinear twodimensional, steady state boundary layer equations for momentum and heat (energy) have been solved with a finite difference scheme, with verification of computational accuracy demonstrated via benchmarking with earlier non-magnetic, no slip, Newtonian solutions in the literature. The present computations have shown that increasing Weissenberg number accelerates the near-wall flow and also increases temperatures (i.e reduces Nusselt number). Stronger magnetic parameter serves to decelerate the flow and to elevate temperatures i.e. decreases Nusselt numbers. With greater momentum slip the flow is accelerated near the cone surface whereas temperatures are depressed i.e. Nusselt numbers are increased. With greater thermal slip surface skin friction and Nusselt number are both significantly suppressed. The present work has ignored transient and porous medium effects in viscoelastic flow (2010) which will be considered in the future.

\section{NOMENCLATURE}

A Half angle of the cone

$B_{0} \quad$ externally imposed radial magnetic field

$C_{f} \quad$ skin friction coefficient

$f \quad$ non-dimensional steam function

Gr Grashof number

$g \quad$ acceleration due to gravity

$k \quad$ thermal conductivity of fluid

$K_{0} \quad$ thermal jump factor

$\mathrm{Nu} \quad$ local Nusselt number

$M \quad$ magnetic body force parameter

Pr Prandtl number

$N_{0} \quad$ velocity (momentum) slip factor

$S_{f} \quad$ non-dimensional velocity slip parameter

$S_{T} \quad$ non-dimensional thermal jump parameter

$T \quad$ temperature

$u, v \quad$ non-dimensional velocity components along the $\mathrm{x}$ - and $\mathrm{y}$ directions, respectively

We Weissenberg (viscoelasticity) number

$x \quad$ stream wise coordinate

$y \quad$ transverse coordinate

\section{Greek Symbols}

$\begin{array}{ll}\alpha & \text { thermal diffusivity } \\ \beta & \text { coefficient of thermal expansion } \\ \eta & \text { dimensionless transverse coordinate } \\ v & \text { kinematic viscosity } \\ \theta & \text { non-dimensional temperature } \\ \rho & \text { density of viscoelastic fluid } \\ \sigma & \text { electrical conductivity of viscoelastic fluid } \\ \xi & \text { dimensionless steam wise coordinate } \\ \psi & \text { dimensionless stream function } \\ \Gamma & \text { time-dependent material constant }\end{array}$

\section{Subscripts}

w $\quad$ conditions on the wall

$\infty \quad$ Free stream conditions

\section{Acknowledgment}

The authors appreciate the constructive comments of the reviewers which led to definite improvement in the paper. The first two authors are thankful to the management of Madanapalle Institute of Technology \& Science, Madanapalle for providing research facilities in the campus.

\section{REFERENCES}

Alam, M.M., Alim, M.A., and Chowdhury, M.M.K., 2007, "Free Convection from a Vertical Permeable Circular Cone with Pressure Work and Non-Uniform Surface Temperature," Nonlinear Analysis: Modelling and Control, 12(1), 21-32.

Alkasasbeh, H.T., Salleh, M.Z., Nazar, R., and Pop, I., 2014, "Numerical Solutions of Radiation Effect on Magnetohydrodynamic Free Convection Boundary Layer Flow about a Solid Sphere with Newtonian Heating," Applied Mathematical Sciences, 8(140), 69897000 .

http://dx.doi.org/10.12988/ams.2014.48649

Aly, A.A., 2015, "Heat Treatment of Polymers: a review," Int. J. Materials Chemistry and Physics, 1(2), 132-140.

Amanulla, C.H., Nagendra, N., Sury a Narayana Reddy, M., Subba Rao, A., and Anwar Bég, O., 2017, "Mathematical Study of Non-Newtonian Nanofluid Transport Phenomena from an Isothermal Sphere," Frontiers in Heat and Mass Transfer, 8, 29.

http://dx.doi.org/10.5098/hmt.8.29

Amanulla, C.H., Nagendra, N., and Sury anarayana Reddy, M., 2017, "Multiple Slip Effects on MHD and Heat Transfer in a Jeffery Fluid over an Inclined Vertical Plate," International Journal of Pure and Applied Mathematics, 113(7), 137-145.

Amanulla, C.H., Nagendra, N., and Surya Naray ana Reddy, M., 2017, "Numerical Study of Thermal and Momentum Slip Effects on MHD Williamson Nanofluid from an Isothermal Sphere," Journal of Nanofluids, 6(6), 1111-1126.

https://doi.org/10.1166/jon.2017.1405

Bég, O.A., Keimanesh, M., Rashidi, M.M., and Davoodi, M., 2013, "Multi-Step DTM Simulation of Magneto-Peristaltic Flow of a Conducting Williamson Viscoelastic Fluid," Int. J. Appl. Math. Mech. 9(6), 1-19.

Bég, O.A., Uddin, M.J., Rashidi, M.M., and Kavyani, N., 2014, "Double-Diffusive Radiative Magnetic Mixed Convective Slip Flow with Biot and Richardson Number Effects," J. Engineering Thermophysics, 23(2), 79-97. http://dx.doi.org/10.1134/S1810232814020015

Bég, O.A., Zueco, J., Norouzi, M., Davoodi, M., Joneidi, A.A., and Elsayed, A.F., 2014, "Network and Nakamura Tridiagonal Computational Simulation of Electrically-Conducting Biopolymer Micro-Morphic Transport Phenomena," Computers in Biology and Medicine, 44, 44-56.

http://dx.doi.org/10.1016/j.compbiomed.2013.10.026

Bég, T.A., Bég, O.A., Rashidi, M.M., and Asadi, M., 2012, "Homotopy Semi-Numerical Modelling of Nanofluid Convection Flow from an Isothermal Spherical Body in a Permeable Regime", Int. J. Microscale Nanoscale Therm. Fluid Transp. Phenom., 3(4), 237-265.

Black, W.B., 2000, "Wall Slip and Boundary Effects in Polymer Shear Flows," PhD Thesis, Chemical Engineering, University of Wisconsin Madison, USA.

Brochard, F., and Gennes, P.G.D., 1992, "Shear-Dependent Slippage at a Polymer/Solid Interface,” Langmuir, 8(12), 3033-3037.

http://dx.doi.org/10.1021/la00048a030

Cheng, C.Y., 2011, "Natural Convection Boundary Layer Flow of a Micropolar Fluid over a Vertical Permeable Cone with Variable Temperature," Int. Commun. Heat Mass Transf. 30(4), 429-433. 
Dapra, I., and Scarpi, G., 2007, "Perturbation Solution for Pulsatile Flow of a Non-Newtonian Williamson Fluid in a Rock Fracture," Int. J. Rock Mechanics and Mining Sciences, 44(2), 271-278. http://dx.doi.org/10.1016/j.ijrmms.2006.07.003

Devi, S.P.A., and Devi, R.U., 2011, "Soret and Dufour Effects on MHD Slip Flow with Thermal Radiation over a Porous Rotating Infinite Disk," Comm. Nonlinear Science and Numerical Simulation, 16(4), 1917-1930.

http://dx.doi.org/10.1016/j.cnsns.2010.08.020

Gaffar, S.A., Prasad, V.R., Reddy, S.K., and Bég, O.A., 2016, "Magnetohydrodynamic Free Convection Boundary Layer Flow of Non- Newtonian Tangent Hyperbolic Fluid from a Vertical Permeable Cone with Variable Surface Temperature," J. Braz. Society Mech. Sci. Eng., 39(1), 101-116.

http://dx.doi.org/10.1007/s40430-016-0611-x

Hatzikiriakos, S.G., and Dealy, J.M., 1992, "Wall Slip of Molten High Density Polyethylenes. II. Capillary Rheometer Studies," J. Rheology, 36(4), 703-741.

http://dx.doi.org/10.1122/1.550313

Hatzikiriakos, S.G., and Dealy, J.M., 1991, "Wall Slip of Molten High Density Polyethylene. I. Sliding Plate Rheometer Studies," J. Rheol., 35(4), 497-523.

http://dx.doi.org/10.1122/1.550178

Harish Babu, D., Satya Naray ana, P.V., (2016), "Joule Heating Effects on MHD Mixed Convection of a Jeffrey Fluid over a Stretching Sheet with Power Law Heat Flux: A Numerical Study," Journal of Magnetism and Magnetic Materials, 412, 185-193.

https://doi.org/10.1016/j.jmmm.2016.04.011

Hay at, T., Shafiq, A., and Alsaedi, A., 2016, “Hydromagnetic Boundary Layer Flow of Williamson Fluid in The Presence of Thermal Radiation and Ohmic Dissipation," Alexandria Engineering J., 55(3), 2229-2240. http://dx.doi.org/10.1016/j.aej.2016.06.004

Hossain, M.A., and Paul, S.C., 2001, "Free Convection from a Vertical Permeable Circular Cone with Non-Uniform Surface Temperature," Acta Mech., 151(1), 103-114.

http://dx.doi.org/10.1007/BF01272528

Jamil, M., and Khan, N.A., 2011, "Slip Effects on Fractional Viscoelastic Fluids," Int. J. Differential Equations, 2011(2011), 1-19. http://dx.doi.org/10.1155/2011/193813

Kasim, A.R.M., Mohammad, N.F., Anwar, I., and Shafie, S., 2013, "MHD Effect on Convective Boundary Layer Flow of a Viscoelastic Fluid Embedded in Porous Medium with Newtonian Heating," Recent Advances in Mathematics, 4, 182-189.

Khan, N.A., and Khan, H., 2014, "Boundary Layer Flows of NonNewtonian Williamson Fluid," Nonlinear Engineering, 3(2), 107-115. http://dx.doi.org/10.1515/nleng-2014-0002

Lim, F.J., and Schowalter, W.R., 1998, "Wall Slip of Narrow Molecular Weight Distribution Polybutadienes," J. Rheol., 33(8), 1359-1382. http://dx.doi.org/10.1122/1.550073

Megahed, A.M., 2012, "Variable Viscosity and Slip Velocity Effects on The Flow and Heat Transfer of a Power-Law Fluid over a Non-Linearly Stretching Surface with Heat Flux and Thermal Radiation," Rheologica Acta, 51(9), 841-847.

http://dx.doi.org/10.1007/s00397-012-0644-8
Meng, H., and Hu, J., 2010, “A Brief Review of Stimulus-Active Polymers Responsive to Thermal, Light, Magnetic, Electric, and Water/Solvent Stimuli," J. Intelligent Material Systems and Structures, 21(9), 859-885.

https://doi.org/10.1177/1045389X10369718

Migler, K.B., Hervet, H., and Leger, L., 1993, "Slip Transition of a Polymer Melt Under Shear Stress," Physical Review Letters, 70, 287 290.

https://doi.org/10.1103/PhysRevLett.70.287

Na, T.Y., and Chiou, J.P., 1979, "Laminar Natural Convection over a Frustum of a Cone," Appl. Sci. Res. 35(5), 409-421.

http://dx.doi.org/10.1007/BF00420389

Nadeem, S., and Saleem, S., 2015, "Analytical Study of Third Grade Fluid over a Rotating Vertical Cone in The Presence of Nanoparticles," Int. J. Heat Mass Transf., 85, 1041-1048.

http://dx.doi.org/10.1016/j.ijheatmasstransfer.2015.02.007

Nagendra, N., Reddy M.V.S, and Jayaraj, B., 2008, "Peristaltic Motion of a Power-Law Fluid in an Asymmetric Vertical Channel," Journal of Interdisciplinary Mathematics, 11(4), 505-519. http://dx.doi.org/10.1080/09720502.2008.10700577

Noghrehabadi, A., Behseresht, A., and Ghalambaz, M., 2013, "Natural Convection Flow of Nanofluids over a Vertical Cone Embedded in Non-Darcy Porous Media,” J. Thermophys. Heat Transf. 27(2), 334341.

http://dx.doi.org/10.2514/1.T3965

Piau, J.M., Kissi, N.E., Toussaint, F., and Mezghani, A., 1995, "Distortions of Polymer Extrudates and Their Elimination Using Slippery Surfaces," Rheol. Acta, 34(1), 40-57.

http://dx.doi.org/10.1007/BF00396053

Piau, J.M., and Kissi, N.E., 1994, "Measurement and Modelling of Friction in Polymer Melts During Macroscopic Slip at The Wall," $J$. Non-Newtonian Fluid Mech., 54, 121-142.

http://dx.doi.org/10.1016/0377-0257(94)80018-9

Pop, I., and Na, T.Y., 1999, "Natural Convection over a Vertical Wavy Frustum of a Cone,” Int. J. Non Linear Mech., 34(5), 925-934. http://dx.doi.org/10.1016/S0020-7462(98)00066-3

Prasannakumara, B.C., Gireesha, B.J., Gorla, R.S.R., and Krishnamurthy, M.R., 2016, "Effects of Chemical Reaction and Nonlinear Thermal Radiation on Williamson Nanofluid Slip Flow over a Stretching Sheet Embedded in a Porous Medium," J. Aerosp. Eng., 29(5).

http://dx.doi.org/10.1061/(ASCE)AS.1943-5525.0000578

Rao, K.S., and Rao, P.K., 2014, "Fully Developed Free Convective Flow of a Williamson Fluid Through a Porous Medium in a Vertical Channel," Int. J. Conceptions on Computing and Information Technology, 2(1), 54-57.

Rao, S.A., Amanulla, C.H., Nagendra, N., Sury a Narayana Reddy, M., and Bég, O. A., 2017, "Computational Analysis of Non-Newtonian Boundary Layer Flow of Nanofluid Past a Vertical Plate with Partial Slip," Modelling, Measurement and Control B, 86(1), 271-295.

Rao, S.A., Amanulla, C. H., Nagendra, N., Bég, O. A., Kadir, A., 2017, "Hydromagnetic flow and Heat Transfer in a Williamson NonNewtonian fluid from a Horizontal Circular Cylinder with Newtonian Heating," Int. J. Appl. Comput. Math., 1-21 http://dx.doi.org/10.1007/s40819-017-0304-x 
Rao, S.A., Amanulla, C.H., Nagendra, N., Surya Narayana Reddy, M., and Bég, O. A., 2017, "Hydromagnetic Non-Newtonian Nanofluid Transport Phenomena Past an Isothermal Vertical Cone with Partial Slip: Aerospace Nanomaterial Enrobing Simulation," Heat Transfer Asian Research.

$\underline{\text { http://dx.doi.org/10.1002/htj.21299 }}$

Rojas, J.A., and Santos, K., 2011, “Magnetic Nanophases of Iron Oxide Embedded in Polymer. Effects of Magneto-Hydrodynamic Treatment of Pure and Wastewater," 5th Latin American Congress on Biomedical Engineering CLAIB 2011 May 16-21, 2011, Habana, Cuba.

Sajid, M., Iqbal, S.A., Naveed, M., and Abbas, Z., 2016, “Joule Heating and Magneto Hydrodynamic Effects on Ferrofluid $\left(\mathrm{Fe}_{3} \mathrm{O}_{4}\right)$ Flow in a Semi-Porous Curved Channel," J. Molecular Liquids, 222, 1115-1120. http://dx.doi.org/10.1016/j.molliq.2016.08.001

Sato, S., Oka, K., and Murakami, A., 2004, "Heat Transfer Behavior of Melting Polymers in Laminar Flow Field," Polymer Engineering and Science, 44(3), 423-432.

http://dx.doi.org/10.1002/pen.20038

Satya Narayana, P.V., and Venkateswarlu, B., 2016, "Heat and Mass Transfer on MHD Nanofluid Flow Past a Vertical Porous Plate in a Rotating System," Frontiers in Heat and Mass Transfer, 7, 8. http://dx.doi.org/10.105098/hmt.7.8

Satya Narayana, P.V., and Harish Babu, D., (2016), "Numerical Study of MHD Heat and Mass Transfer of a Jeffrey Fluid over a Stretching Sheet with Chemical Reaction and Thermal Radiation," Journal of the Taiwan Institute of Chemical Engineers, 59, 18-25.

http://dx.doi.org/10.1016/j.jtice.2015.07.014

Sreenadha, S., Govardhana, P., and Kumar, Y.V.K.R., 2014, "Effects of Slip and Heat Transfer on The Peristaltic Pumping of a Williamson Fluid in an Inclined Channel," Int. J. Appl. Sci. Eng., 12(2), 143-155.

Stepanov, G.V., Abramchuk, S.S., Grishin, D.A., Nikitin, L.V., Kramarenko, E., and Khokhlov, A.R., 2007, "Effect of a Homogeneus Magnetic Field on The Viscoelastic Behavior of Magnetic Elastomers," Polymer, 48(2), 488-495.

http://dx.doi.org/10.1016/j.polymer.2006.11.044
Tripathi, D., Bég, O.A., and Curiel-Sosa, J.L., 2014, "Peristaltic Flow of Generalized Oldroyd- B Fluids with Slip Effects," Computer Methods in Biomechanics Biomedical Engineering, 17(4), 433-442. http://dx.doi.org/10.1080/10255842.2012.688109

Venkateswarlu, B. and Satya Narayana, P.V., 2016, "Influence of Variable Thermal Conductivity on MHD Casson Fluid Flow over a Stretching Sheet with Viscous Dissipation, Soret and Dufour Effects," Frontiers in Heat and Mass Transfer, 7, 16.

http://dx.doi.org/10.5098/hmt.7.16

Yamaguchi, H., Zhang, X.R., Higashi, S., and Li, M., 2008, "Study on Power Generation Using Electro-Conductive Polymer and Its Mixture with Magnetic Fluid," J. Magnetism and Magnetic Materials, 320(7), 1406-1411.

http://dx.doi.org/10.1016/j.jmmm.2007.12.014

Yarin, A.L., and Graham, M.D., 1998, "A Model for Slip at Polymer/Solid Interfaces,” J. Rheol., 42(6), 1491-1504.

http://dx.doi.org/10.1122/1.550898

Yih, K.A., 1999, "Effect of Radiation on Natural Convection about a Truncated Cone," Int. J. Heat Mass Transf. 42(23), 4299-4305. http://dx.doi.org/10.1016/S0017-9310(99)00092-7

Yonemura, H., Takata, M., and Yamada, S., 2014, "Magnetic Field Effects on Photoelectrochemical Reactions of Electrodes Modified with Thin Films Consisting of Conductive Polymers," J. Appl. Phys. 53.

Zengyu, X., Chuanjie, P., Weihong, J., Wenhao, W., Wenzhong, L., and Jiapu, Q., 1998, "MHD Effects Caused by Insulator Coating Imperfections," Fusion Engin. Design, 39-40(1), 739- 798. http://dx.doi.org/10.1016/S0920-3796(98)00303-2

Zueco, J., Bég, O.A., and Ghosh, S.K., 2010, "Unsteady Natural Convection of a Short-Memory Viscoelastic Fluid in a Non-Darcian Regime: Network Simulation," Chemical Engineering Communications, 198(2), 172-190.

http://dx.doi.org/10.1080/00986445.2010.499842 